\title{
Distribution, naturalization status, invasion history and plant communities of Impatiens glandulifera Royle (Balsaminaceae) in Siberia
}

\author{
Alexander Ebel $^{1,2, *}$ Wojciech Adamowski ${ }^{3}$, Svetlana Mikhailova ${ }^{1,4}$, Alla Verkhozina $^{5}$, Elena \\ Zykova $^{2}$ and Svetlana Sheremetova ${ }^{6}$ \\ ${ }^{1}$ Tomsk State University, Tomsk, Russia, 634050, 36 Lenin av. \\ ${ }^{2}$ Central Siberian Botanical Garden SB RAS, Novosibirsk, Russia \\ ${ }^{3}$ Białowieża Geobotanical Station, Faculty of Biology, University of Warsaw, Sportowa 19, \\ Białowieża, 17-230, Poland \\ ${ }^{4}$ Tomsk Branch of All-Russian Plant Quarantine Center ("VNIIKR"), Tomsk, Russia \\ ${ }^{5}$ Siberian Institute of Plant Physiology and Biochemistry of SB RAS, Irkutsk, Russia \\ ${ }^{6}$ Federal Research Centre for Coal and Coal Chemistry SB RAS, Kemerovo, Russia
}

\begin{abstract}
All available data on the distribution of Impatiens glandulifera Royle in Siberia was analyzed. The species appeared in Siberia as an unpretentious ornamental plant around the middle of the 20th century. Cases of withdrawal from culture have been recorded since the 1970s and 1980s; mass naturalization began at the end of the 20th century. Currently, the species is common in many regions of Siberia, but the most active in the Altai Territory, the Altai Republic, Kemerovo, Novosibirsk, Tomsk and Irkutsk Regions. It is common in anthropogenic habitats; it can also often be found in suburban forests, ravines, along the banks of water bodies. It shows tolerance to habitat conditions, but is especially active in areas with a close occurrence of groundwater on humus-rich soils. The species richness of I. glandulifera communities is from 10-15 to 40 species. In total, about 100 species of vascular plants were recorded in $I$. glandulifera communities in Siberia
\end{abstract}

Impatiens glandulifera Royle (Himalayan Balsam) is an annual plant, which is currently one of the most aggressive alien species in Europe [1-2]. The natural range of $\mathrm{I}$. glandulifera is the Western Himalayas, where this species grows along river banks, in floodplain forests and in ruderal places, at altitudes of 1600-4300 m above sea level [3]. For the first time I. glandulifera was brought to Europe (Great Britain) in 1839 as a garden ornamental plant, and in 1855 this species was already noted in England as "escaped" from culture [4]. There is also information about the earlier cultivation of this species in Europe,

\footnotetext{
*Corresponding author: alex-08@mail2000.ru
} 
namely from 1823 [5]. To date, I. glandulifera is found in 35 European countries, and in 25 countries it is already a naturalized species [6].

A review of information on the distribution of I. glandulifera in Siberia was compiled on the basis of analysis of field research data, herbarium materials, literature sources, databases on alien plants, as well as internet platforms (iNaturalist, Plantarium). Herbarium materials stored in MW, NS, NSK, TK, IRK, IRKU, ALTB, KUZ, KRAS were reviewed. We collected and analyzed information about new localities discovered in recent decades on the territory of Siberia. Field studies were carried out in 1990-2020 in Siberia (Altai, Krasnoyarsk, and Zabaykalskiy Kray, Kemerovo, Omsk, Tomsk, Novosibirsk and Irkutsk Regions, Republics of Altai, Khakassia, Buryatia, and Tuva).

It was not possible to find exact data on the time of the beginning of I. glandulifera cultivation on the territory of Siberia. According to indirect indications, this species has been cultivated in the region, probably since the middle of the 20th century. Apparently, escaping from culture and mass naturalization began relatively recently. So, in the "Flora of Siberia" I. glandulifera is mentioned only in the notes, reference to the only herbarium collection from the Altai Kray: environs of the Belokurikha resort, dated 1973 [7]; the plant grew, as follows from the label, "along the banks of the Belokurikha River near the water" (NS!). The next herbarium collection known to us was also made in Northern Altai (GornoAltaysk) in 1980 (https://plant.depo.msu.ru/open/public/item/MW0111136). At the end of the 1970s I. glandulifera was rather widely grown in Kemerovo Region. One of authors (WA) observed it in 1992 in ruderal and seminatural vegetation in Novosibirsk near Ob River. Starting from the 1990s, information began to appear about cases of naturalization of Himalayan Balsam in most regions of Siberia (see map). To date, I. glandulifera has been found in many areas of Siberia, from the Trans-Urals to the Zabaykalye (for references see: [7]). Within Siberia, this species is the most invasive in 6 constituent entities of the Russian Federation: Altai Kray, Altai Republic, Kemerovo, Novosibirsk, Tomsk and Irkutsk Regions (see map).

The northernmost known locations in Siberia are: Surgut, $61.273342 \mathrm{~N}$ (https://www.inaturalist.org/observations/55286460), Kolpashevo, $\quad 58.306563 \mathrm{~N}$ (https://www.inaturalist.org/observations/57005248), Bodaibo, $\quad 57.855555 \mathrm{~N}$ (https://www.plantarium.ru/lang/en/page/image/id/36650.html), and Tommot, $58.96666 \mathrm{~N}$ (https://www.plantarium.ru/lang/en/page/image/id/543922.html). Distribution of Himalayan Balsam in Siberia is limited by its high demand for moisture and sensitivity to frost.

A number of circumstances contribute to the wide expansion of Himalayan Balsam in the southern regions of Siberia: large areas of old buildings in settlements with private houses and front gardens, the presence of ruderal vegetation, as well as favorable soil and climatic conditions. Being one of the most unpretentious ornamental plants used in mass culture, I. glandulifera is still widely cultivated in a number of settlements in Siberia, renewing itself mainly by self-sowing. The frequency of occurrence of spontaneous populations in urbanized areas is sometimes higher than in culture: this is evidenced by the published data for Irkutsk [8] and by our observations in Tomsk. On the other hand, the low-mountain humid regions of southern Siberia are highly susceptible to the expansion of this species, among them the Northern Altai, Gornaya Shoria, and Khamar-Daban.

Within the phytosociological classification (J. Braun-Blanquet's approach), $I$. glandulifera belongs to the diagnostic species of the Galio-Urticetea Passarge ex Kopecký 1969 class, which unites in Europe natural and anthropogenic tall-grass nitrophilous communities of shaded habitats in forest parks and squares, on forest edges and in floodplains of rivers [9]. Communities with I. glandulifera are considered in the rank of the association Calystegio sepium-Impatientetum glanduliferae Hilbig 1972 of this class [10]. 


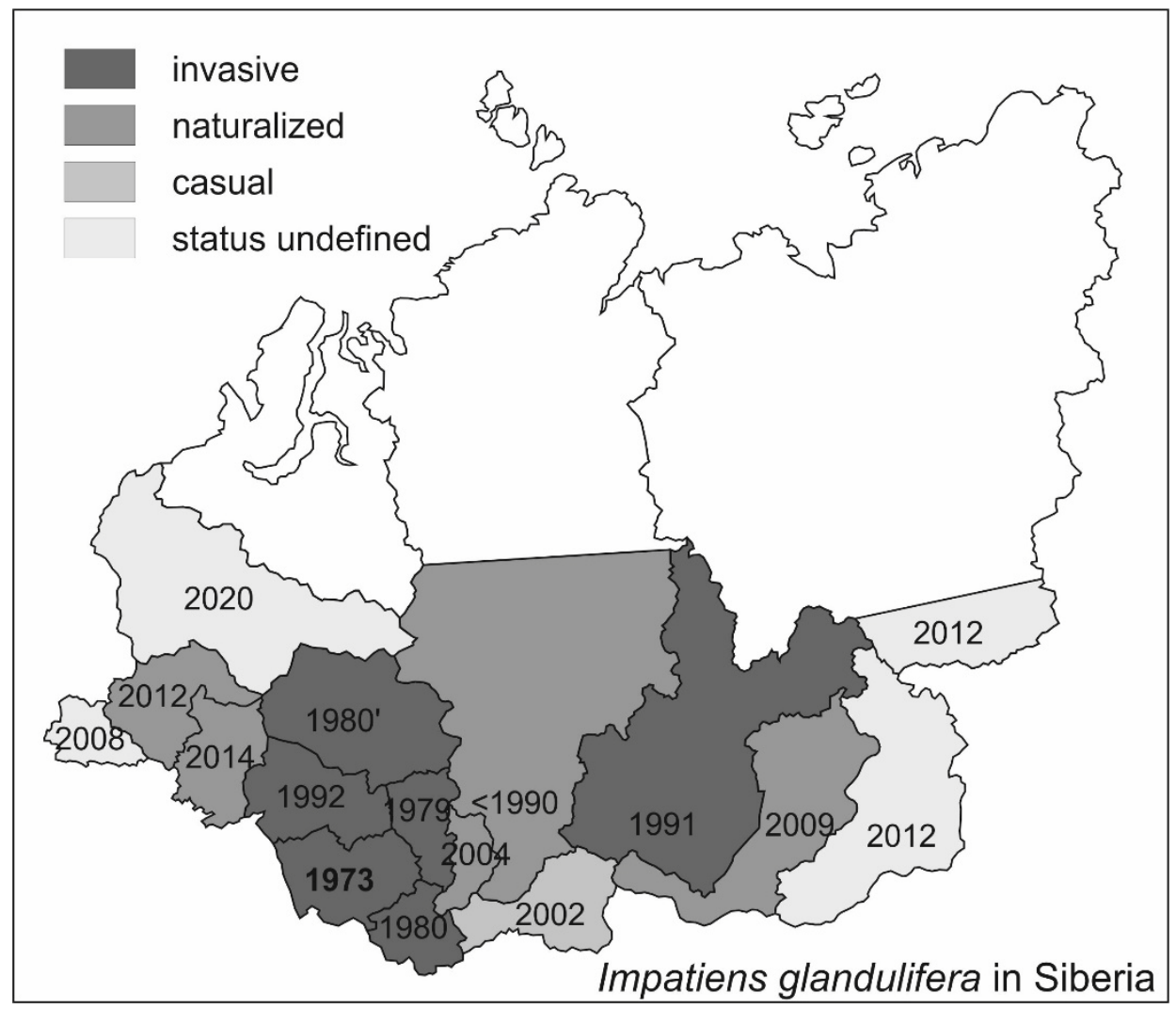

Fig. 1. Impatiens glandulifera in Siberia

On the territory of Siberia, this species grows mainly in anthropogenic habitats: dumps and wastelands, abandoned household plots, near fences and garages, on roadsides, in unkempt areas of city parks. Himalayan Balsam shows tolerance to "soil" conditions, sometimes growing on very exotic substrates: from heaps of various household and construction waste to practically pure manure. This species can often be found in habitats close to natural: ravines, suburban forests (mainly in shady and damp places), banks of reservoirs, rocky taluses along the banks of rivers. We observed stable populations of $I$. glandulifera in urban forests located in the recreational zone. In Altai Krai, this species was recorded on burnt-out areas in pine forests (https://www.plantarium.ru/lang/en/page/flora/id/58.html). Himalayan Balsam grows particularly abundant in areas with a close occurrence of groundwater on humus-rich soils, forming communities together with synanthropic species: Arctium tomentosum Mill., Chenopodium album L., Cirsium setosum (Willd.) Besser, etc. Artemisia vulgaris L., a constant species of the association Calystegio sepium-Impatientetum glanduliferae Hilbig 1972 , is quite often present in the communities of I. glandulifera; occasionally there are 2 more constant species of association: Aegopodium podagraria L. and Calystegia sepium (L.) R. Br. (the latter is one of the diagnostic species of this association). Urtica dioica L. (diagnostic species of the class Galio-Urticetea) is almost always present; other diagnostic species of this class are less common: Carduus crispus L., Chelidonium majus L., Geum aleppicum Jacq., G. urbanum L., Impatiens parviflora DC., etc. Some invasive plants grow relatively often in I. glandulifera communities: Acer negundo L., Conyza canadensis (L.) Cronquist, Lactuca serriola L., etc. According to our investigation, there are about 100 
vascular plant species in I. glandulifera communities in Siberia. The species richness of such communities varies from 10-15 species per 100 square meters in the case of a high abundance of I. glandulifera (4-5 points on the Brown-Blanquet scale) or in highly shaded habitats up to 40 species at the initial stage of formation of I. glandulifera community on garbage dumps.

The work was carried out with particular support of the RFBR and Administration of Kemerovo Region, Grant № 20-44-420007 r_a (Outworking of the integrated information system "Kuzbass Digital Herbarium").

\section{References}

1. D.J. Beerling, D.M. Perrins, Journ. Ecol. 81, 367-382 (1993)

2. K. Helsen, M. Diekmann, G. Decocq, K. De Pauw, S. Govaert, B.J. Graae, J. Hagenblad, J. Liira, A. Orczewska, P. Sanczuk, K. Van Meerbeek, P. De Frenne, Perspectives in Plant Ecology, Evolution and Systematics, 50, 1-21 (2021)

3. Y.J. Nasir, Flora of Pakistan, 133 (1980) [Online]. http://legacy.tropicos.org/Name/3100049?projectid=32, Date of access 20/07/2021/

4. J. Britten, J. Bot., 38, 50-51 (1900)

5. M.V. Markov, N.G. Ulanova, N.V. Chubatova, Biological flora of the Moscow region. (Moscow, 1997)

6. P.W. Lambdon, P. Pyšek, C. Basnou, M. Hejda, M. Arianoutsou, F. Essl, V. Jarošík, J. Pergl, M. Winter, P. Anastasiu, P. Andriopoulos, I. Bazos, G. Brundu, L. CelestiGrapow, P. Chassot, P. Delipetrou, M. Josefsson, S. Kark, S. Klotz, Y. Kokkoris, I. Kühn, H. Marchante, I. Perglová, J. Pino, M. Vilà, A. Zikos, D.B. Roy, P.E. Hulme, Preslia, 80, 101-149 (2008)

7. S.I. Mikhailova, A.L. Ebel, Black book of the flora of Siberia (Novosibirsk, 2016)

8. V.V. Chepinoga, S.V. Solodyankina, V.P. Ivanova, Bulletin of the Tomsk State University. Biology. 2 (34), 87-100

9. L. Mucina, Folia Geobot., 32 (2), 117-172 (1997)

10. M. Chytrý Vegetace České republiky. 2. Ruderální, plevelová, skalní a sut'ová vegetace (Praha, 2009) 